\title{
The Mediating Role of Trust for Inter-Organizational Information Sharing (IIS) Success in the Public Sector by Djoko Sayogo
}

Submission date: 24-Mar-2019 07:52PM (UTC-0700)

Submission ID: 1099097025

File name: ational_Information_Sharing_IIS_Success_in_the_Public_Sector.pdf (351.79K) Word count: 7584

Character count: 43162 


\section{The Mediating Role of Trust for Inter-Organizational Information Sharing (IIS) Success in the Public Sector}

\author{
Djoko Sigit Sayogo \\ University of Muhammadiyah Malang \\ Jl. Raya Tlogomas no. 246 \\ Malang, Indonesia \\ dsayogo@ctg.albany.edu
}

\author{
J. Ramon Gil-Garcia \\ University at Albany, State University \\ of New York \\ 187 Wolf road, Suite 301 \\ Albany, New York \\ jgil-garcia@ctg.albany.edu
}

Bambang Widagdo

University of Muhammadiyah Malang

Jl. Raya Tlogomas no. 246

Malang, Indonesia

bwidagdo@gmail.com

\author{
Felippe A. Cronemberger \\ University at Albany, State University \\ of New York \\ 1400 Washington Ave \\ Albany, New York \\ fcronemberger@albany.edu
}

\begin{abstract}
Interagency collaboration and information sharing in the public sector is a complex enterprise laden with risks. In this type of environment, past studies find that trust is key to the success of inter-organizational information sharing (IIS) initiatives. Based on a review of current literature and a national survey conducted in the US, this paper quantitatively explores the role of trust in mediating the relationship between multiple variables and the success in IIS. Overall, we found that trust is significant in mediating the relationships among four determinants of IIS success, namely: a) effective communication, b) clarity about their roles and responsibilities and expectations about other participants' roles and responsibilities, c) competence inferred from past experiences, and d) judicious exercise of formal authority, which reduces participants' uncertainty and anxiety about the project. Furthermore, our analysis indicates that the role of trust in mediating the relationships depends on how success is measured in an IIS pr 1 ject. Testing the roles that trust plays through statistical analysis makes an important contribution to the literature, as well as to government practice.
\end{abstract}

\section{CCS CONCEPTS}

- Applied computing $\rightarrow$ Computing in government, $E$ government

\section{Keywords}

Inter-organizational information sharing, trust, clarity of roles, collaboration.

Permission to make digital or hard copies of all or part of this work for personal or classroom use is granted without fee provided that copies are not made or distributed for profit or commercial advantage and that copies bear this notice and the full citation on the first page. Copyrights for components of this work owned by others than ACM must be honored. Abstracting with credit is permitted. To copy otherwise, or republish, to post on servers or to redistribute to lists, requires prior specific permission and/or a fee. Request permissions from Permissions@acm.org dg.o '17, June 07-09, 2017, Staten Island, NY, USA

C 2017 Association for Computing Machinery. ACM ISBN 978-1-4503-5317-5/17/06 _.\$15.00 http://dx.doi.org/10.1145/3085228.3085236

\section{INTRODUCTION}

Developing and executing smart, efficient, and more responsive public policies and programs to face contemporary social problems requires the foundational capability to integrate and share information [37]. Collaborative activities are crucial components for integrating and sharing information among participants across policy domains and organizations $[8,9]$. In fact, research suggests that ensuring effective collaboration is more crucial than the technology itself to drive a successful information integration and sharing project [9].

Trust is an essential relational component of collaboration because it facilitates successful interactions and processes [7, 17] Working in transboundary collaboration can be challenging for government officials who are not accustomed to working across their respective jurisdictional and organizational boundaries [8] Hence, trust is the key in securing ongoing and workable relationships among the disparate participants that form a collaboration [6]. It is vital to develop trust early in the collaboration [6] given the often limited time and opportunities to build up trust between the participants $[6,26]$. Likewise, the combination of individual trust and a trusted network is regarded as one of the pillars of interagency information integration and sharing $[12,23]$

Nonetheless, an agency's culture, division of labor, and specialization often challenge the efforts of each participant to share and collaborate in information sharing initiatives in the public sector [29]. Under the above conditions, it is not easy for government professionals to untangle their rigid alliance to their own agency, service, or discipline [17]. As government officials are more accustomed to a "need to know" rather than a "need to share" culture [9], the professional identities and agency cultures that isolate practice domains and knowledge resources potentially obstruct the creation of trust in an information integration and sharing project [29]. As shown in the case of the interagency Pacific Salmon Commission, trust across different organizations and jurisdictions can be relatively low [40]. 
Given prior research about the importance of trust for collaborative relationships in interagency information integration and sharing initiatives [17], we need to better understand how participants establish that trust [22]. As such, this paper aims to provide a preliminary assessment of the determinants that in fluence trust in interagency collaboration for information integration and sharing through quantitative analysis. To that end, this paper addresses two research questions: a) What are the determinants of trust in an information integration and sharing project? b) How does trust affect the success of information integration and sharing projects?

This study analyzed data collected from a national survey evaluating interagency information integration and sharing in the US, using Structural Equation Modelling to test multiple relevant hypotheses. An information integration and sharing project, as defined in this paper, refers to initiatives that develop information sharing or communication capabilities that involve two or more government agenci 5 (abbreviated as IIS hereafter). The survey was distributed to public managers and other actors involved in public health and criminal justice information integration initiatives at the state and local levels in the US. The pub 5 health cases focused on local and state government responses to West Nile virus outbreaks in Colorado, Oregon, Connecticut, and New York. The criminal justice cases included inter-agency information integration initiatives at the state level in New York, North Carolina, and Colorado, and at the local level in New York City. The determinants of trust in this study were identified in existing literature, particularly Pardo, Gil-Garcia and Burke [30] and GilGarcia, Guler, Pardo and Burke [11].

\section{The Role of Trust in IIS Projects}

While the concept of trust is mostly discussed at the interpersonal level, research suggest that it can be extended to interorganizational and cross-boundary relationships [27]. There are three most frequently discussed constructs of trust at the interpersonal level, as argued by Mayer et al. [24]: ability, benevolence, and integrity. However, it is argued that the three constructs 11 t define interpersonal trust - ability, benevolence, and integrity - can also be applied at the inter-organizational level if these features are viewed as the features of organizations [39, 27]. This application works because inter-organizational information integration and sharing in the public sector consists of interconnecting layers where the interpersonal relations among the participants form its very basic structure [44].

At the inter-organizational level, trust is based on implicit assumptions, positive expectations, and confidence that the other party in the collaboration will perform acts to achieve the group's common goals $[27,11]$. Based on qualitative analysis from case studies of interagency information integration and sharing for health policy and criminal justice, Gil-Garcia et al. [11] and Pardo 1 al. [30] proposed three major determinants of trust for IIS: a) clarity of roles and responsibilities, b) knowledge of participating organizations, and c) exercise of authority.

Clarity of roles and responsibilities (abbreviated as CRRs hereafter) in an information sharing project can help build trust among members [29]. CRRs precipitate the formation of mutual expectations about outcomes and how the participants in the collaborative effort will behave $[41,43]$. Therefore, the formation of participants' expectations about the contributions that their own organization and others 1 make to the IIS initiative can be augmented by having a clear delineation of roles and responsibilities in IIS $[12,19,30]$. A shared understanding of the role expectations will increase the perception of individuals that they have salient information to effectively enact their roles in the collaboration, hence reducing role ambiguity [1993] and reducing the risks of opportunistic behavior in the collaboration [13, 27]. The presence of CRRs facilitate the development of trust to help them interact effectively with one another, alleviating the burden on participants [36].

Greater diversity poses the potential for greater conflict, but sensitivity to the different interests of the participating organizations can help the project leaders to delineate roles and responsibilities that minimize these potential conflicts and facilitate the building of trust [29]. Acknowledging and acting on the differences among the participants facilitate the creation of CRRs and in turn the forma $10 \mathrm{n}$ of trust in an IIS project. As such, knowledge about the participating organizations influer $1 \mathrm{~s}$ the development of trust relationships among the collaborative partners through a better understanding of one another's interests, capabilities, and operating styles $[12,16]$.

There is a wide range and distribution of power and authority relationships in interagency collaboration due to the diversity of the agencies involved; no single agency has the authority to decide and impose the roles and responsibilities of other agencies involved in the collaboration. Hence, a judicious process for how to exercise formal authority is necessary to build trust and enable effective collaboration (Pardo et al., 2009). The existence of proper authority and a cautious way of exercising that formal authority influence the development of trust among the participants in collaborative settings [30]. Being respectful of the autonomy of participating organizations through the careful exercise of formal authority in interagency collaboration also facilitates trust building [12].

Experiences and interactions in prior collaborations also influence the development of trust. Past experiences and interactions provide references for future expectations regarding the participants in the collaboration [3]. Repeated interactions through working together in previous collaborative projects creates familiarity and showcases the credibility of the participants that leads to the development of trust in the collaboration [1,2].

Communication skills are at the heart of any collaborative effort, particularly to facilitate the development of trust $[5,15,22]$. Communication and collaboration skills are crucial because learning each other's objectives, roles, and constraints is the starting point fo 1 an inter-organizational initiative [22]. Communication ensures continued interaction between participating organizations, which enables trust buil, ing relationships [20]. Furthermore, communication, particularly raceto-face communication, is a crucial factor in enhancing trust among the participants in collaboration because the participants can assess other participants' trustworthiness through face-to-face communication [28]. Intensive conversations among the participants in collaboration provide a medium for the participants to better understand each other's interests, capabilities, and operating styles, leading to the development of trust [15]. Based on this literature review, we propose the following model and hypotheses.

$\mathrm{H}_{1}$ : Trust significantly and directly affects IIS project success.

$\mathrm{H}_{2}$ : Trust significantly mediates the role of effective communications in influencing IIS project success.

$\mathrm{H}_{3}$ : Trust significantly mediates the role of clarity of roles and responsibilities in influencing IIS project success. 
$\mathrm{H}_{4}$ : Trust significantly mediates the role of the participant's experiences in influencing IIS project success.

$\mathrm{H}_{5}$ : Trust significantly mediates the role of judicious exercise of formal authority in influencing IIS project success.

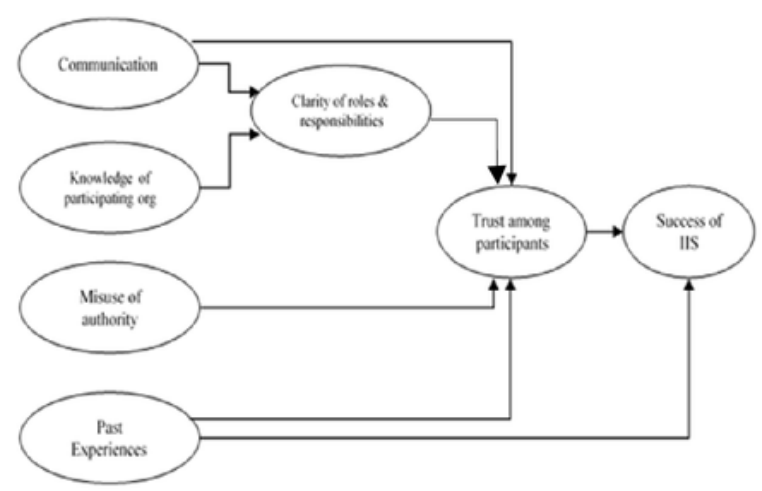

Figure 1. The Proposed Model of Trust's Influence on IIS Success

\section{Research Design and Method}

This section briefly describes the research design and methods used for this study, including the data collection, the measurement of the variables, and the analysis techniques. Considering our interest in testing the direct and indirect relationships linking trust and the success of IIS, the data were analyzed using Structural Equation Modeling (SEM) techniques to account for the endogenous and exogenous relationships among the variables. The following subsections provide more detail about our data and analysis techniques.

\subsection{Data and Data Collection}

This study analyzes data from a national survey conducted by the Center for Technology in Government, University at Albany, SUNY in April 2008. The use of older data should not pose a problem because this study aims to test theory and it is therefore expected that the relationships among the variables is generalizable and stable over time. The original random-sampled dataset consists of 171 responses, with their demographic distribution reported in Table 1. After data cleaning, the SEM analysis was based on 158163 responses and about $7-8 \%$ of the responses were dropped from the analysis due to issues of missing data.

The proportion of survey respondents was relatively even for both policy domains with $56 \%$ of respondents from the public health domain and $44 \%$ from criminal justice. The majority of the survey respondents $(82 \%)$ were involved in IIS initiatives across agencies, across levels of government, and across multiple levels of government and with non-government organizations. More than a third of the respondents $(39 \%)$ indicated that state government provided the funding for the IIS initiative. Subsequently, the primary initiative coordinator for most of the IIS initiatives was from state government $(61 \%)$, followed by local government $(25 \%)$. Not-for-profit organizations provided about $4 \%$ of the primary initiative coordination.

The majority of survey respondents work for local governments $(56 \%)$, followed by state governments $(29 \%)$. Most of these respondents have positions as executives $(34 \%)$ or program managers $(36 \%)$. The proportion of male respondents was higher than female respondents by $16 \%$. The proportion of male respondents was higher in the criminal justice policy domain as compare to the public health domain. Almost all respondents had acquired at least one year of experience working in their respective field, with only $3 \%$ of the respondents indicating that they had acquired less than a year of work experience at the time of the survey.

\subsection{Variable Measurements}

As mentioned before, we are interested in testing the influence of the determinants on two endogenous variables: a) trust and b) the success of IIS. All items in the questionnaire were rated on a sevenpoint Likert-type scale, characterizing statements as being from "not at all" (1) to "to a great extent" (7) similar to the respondent's experience with IIS. A summary of the variables in the model is provided in Table 2 and descriptions of each variable and their measurement are provided below.

\section{a. Exogenous Variables}

- Exercise of formal authority [auth]. We use a negative measure for exercise of 4 thority. The survey question asked whether leaders and/or participants misused the power of their official positions.

- Collaboration and communication skills [colcom]. This variable measures the extent to which communication within the IIS initiatives was effective

- Past experiences [exp]. This is a composite variable consisting of two questions indicating the extent to which the participants had previous and positive experiences working together as a group. Chronbach's alpha test for the reliability of the measurement of this variable is 0.8209 , which indicates good reliability.

- Knowledge about other participating organizations [know] This variable is a composite variable consisting of four constructs indicating whether the participants are knowledgeable about the 4 relevant business processes, organizational policies, information technologies, and management practices of the other participating organizations involved in the collaboration. Chronbach's alpha test for the reliability of the measurement of this variable is 0.9162 , which indicates good reliability.

- Clarity of roles and responsibilities [crr]. This composite variable measures the extent to which the roles and responsibilities of organizations participating in the IIS project were clear to the participants. It consists of two sub-variables indicating the extent to which the 4 respondent's organization and the other participating organization's roles and responsibilities were clear to the respondent. Chronbach's alpha test for the reliability of the measurement of this variable is 0.8149 , which indicates good reliability.

\section{b. Endogenous Variables}

There are two endogenous variables in this study: a) trust and b) the success of interagency information sharing (IIS) projects.

1. Trust. This variable measures the extent to which the participants trusted each other in the IIS project that they were involved in.

2. Success of IIS. We adopt Eglene et al.'s (2007) argument and measure the success of IIS projects as follows:

- Overall success [allsuc]. This variable measures whether the IIS participants consider that, taken as a whole, the project was a success. 
- Met the policy objectives [polsuc]. This variable measures whether the participants agree that the project met its stated policy objectives and goals.

- Technology success [tecsuc]. This is a composite variable consisting of three constructs measuring technical success. The construct asks the participants whether they agree that 4 e project is a technological success in terms of creating a) information systems that can communicate with each other,

b) interoperable computer systems and networks, and c) new data resources that integrate disparate databases. The reliability of this variable as measured by Chronbach's alpha is 0.8757 .

- Organizational success [orgsuc]. We define this composite variable as measurement of success in terms of the benefits that IIS brings to the organization. We measure the benefits to organizations in five ways: a) improvement in the dayto-day operations of government, b) greater effectiveness of policy deliberation, c) improved efficiency, d) direct benefits to people, groups, and organizations, and e) cost savings. This is also a reliable composite variable w0polith Chronbach's alpha of 0.8589 .

Table 1. Crosstab of Sample Distribution

\begin{tabular}{|c|c|c|c|c|}
\hline \multirow{2}{*}{\multicolumn{2}{|c|}{ Categories }} & \multicolumn{3}{|c|}{ Types of Policy Domain } \\
\hline & & \multirow{2}{*}{$\begin{array}{r}\begin{array}{l}\text { Public } \\
\text { Health }\end{array} \\
8 \%\end{array}$} & \multirow{2}{*}{$\begin{array}{r}\begin{array}{c}\text { Criminal } \\
\text { Justice }\end{array} \\
5 \%\end{array}$} & \multirow{2}{*}{$\begin{array}{c}\begin{array}{c}\text { Both } \\
\text { Domain }\end{array} \\
6 \%\end{array}$} \\
\hline Primary & Federal government & & & \\
\hline Initiative & State government & $65 \%$ & $56 \%$ & $61 \%$ \\
\hline \multirow[t]{5}{*}{ Coordinator } & Local government & $19 \%$ & $32 \%$ & $25 \%$ \\
\hline & Private entity & $0 \%$ & $0 \%$ & $0 \%$ \\
\hline & Non-profit organization & $5 \%$ & $3 \%$ & $4 \%$ \\
\hline & Other (e.g., council of government) & $3 \%$ & $4 \%$ & $4 \%$ \\
\hline & All Categories & $100 \%$ & $100 \%$ & $100 \%$ \\
\hline \multirow{7}{*}{$\begin{array}{l}\text { Initiative's } \\
\text { boundary }\end{array}$} & 4 cross units & $12 \%$ & $3 \%$ & $8 \%$ \\
\hline & Across agencies at the same level of government & $19 \%$ & $28 \%$ & $23 \%$ \\
\hline & Across levels of government & $20 \%$ & $50 \%$ & $33 \%$ \\
\hline & Across one level of government with non-government organization(s) & $10 \%$ & $3 \%$ & $7 \%$ \\
\hline & $\begin{array}{l}\text { Across multiple levels of government with non-government } \\
\text { organization(s) }\end{array}$ & $34 \%$ & $17 \%$ & $26 \%$ \\
\hline & Other (e.g., multi-nationals) & $5 \%$ & $0 \%$ & $3 \%$ \\
\hline & All Categories & $100 \%$ & $100 \%$ & $100 \%$ \\
\hline \multirow[t]{8}{*}{ Funder } & Federal government & $24 \%$ & $9 \%$ & $17 \%$ \\
\hline & State government & $34 \%$ & $45 \%$ & $39 \%$ \\
\hline & Local government & $15 \%$ & $36 \%$ & $24 \%$ \\
\hline & Private entities & $4 \%$ & $1 \%$ & $3 \%$ \\
\hline & Non-govemmental organizations & $10 \%$ & $0 \%$ & $6 \%$ \\
\hline & No funding & $11 \%$ & $5 \%$ & $8 \%$ \\
\hline & Other funding arrangements & $2 \%$ & $4 \%$ & $3 \%$ \\
\hline & All Categories & $100 \%$ & $100 \%$ & $100 \%$ \\
\hline \multirow[t]{8}{*}{ Employment } & Federal agencies & $6 \%$ & $7 \%$ & $6 \%$ \\
\hline & Local agencies & $69 \%$ & $50 \%$ & $60 \%$ \\
\hline & State agencies & $23 \%$ & $36 \%$ & $29 \%$ \\
\hline & Private entities & $0 \%$ & $1 \%$ & $1 \%$ \\
\hline & Non-governmental organizations & $1 \%$ & $3 \%$ & $2 \%$ \\
\hline & Academics & $1 \%$ & $0 \%$ & $0 \%$ \\
\hline & Other (e.g., independent consultants) & $0 \%$ & $3 \%$ & $1 \%$ \\
\hline & All Categories & $100 \%$ & $100 \%$ & $100 \%$ \\
\hline \multirow{6}{*}{$\begin{array}{l}\text { Years of } \\
\text { Experience }\end{array}$} & 0 years & $2 \%$ & $4 \%$ & $3 \%$ \\
\hline & $1-5$ years & $42 \%$ & $32 \%$ & $37 \%$ \\
\hline & $6-15$ years & $38 \%$ & $47 \%$ & $42 \%$ \\
\hline & $16-25$ years & $11 \%$ & $9 \%$ & $10 \%$ \\
\hline & $>25$ years & $7 \%$ & $8 \%$ & $8 \%$ \\
\hline & All Categories & $100 \%$ & $100 \%$ & $100 \%$ \\
\hline \multirow[t]{4}{*}{ Sex } & Male & $54 \%$ & $64 \%$ & $58 \%$ \\
\hline & Female & $46 \%$ & $36 \%$ & $42 \%$ \\
\hline & All Categories & $100 \%$ & $100 \%$ & $100 \%$ \\
\hline & Average proportions of respondents & $56 \%$ & $44 \%$ & \\
\hline
\end{tabular}




\subsection{Analysis Techniques}

Data analysis in this study was conducted in two stages. During the first stage, we identified the variables of interest from the survey. Principal component analysis was used to create and 3 mmarize the composite variables. As previously mentioned, the reliability of the resulting variables was examined using Chronbach's alpha values as well as by considering the unique variances of the variable. After principal component analysis, the scores of the components were computed and used as the value of the composite variables. We forced a one-factor solution in each instance. Subsequently, 13 second stage tested the structural model. We employed the Structural Equation Modeling approach using Lisrel 8.80

\section{ANALYSIS AND RESULTS}

This section consists of two sub-sections presenting the results of our analysis. The first sub-section explains how participants measured the success of their IIS projects, while the second subsection explains the impact of each of the determinants on trust and IIS success and some of the relationships among them.

\subsection{Measuring Success in Inter- Organizational Information Sharing and Integration}

The success of a collaborative project can be measured in various ways based on the perceptions of different project stakeholders [10,31]. In IIS projects, each stakeholder could have different perceptions of success. Based on the survey results, we identify and measure success based on three interrelated components of IIS: policy, technology and organization. In addition, we also measure success as the stakeholder's perception of the overall success of the project.

Our results in Figure 2 indicate that the majority of respondents $(93 \%)$ agree to a certain degree $(25 \%)$ or to a great extent $(69 \%)$ that, taken as a whole, the IIS project was a success. We found similar results when success is measured by whether the project met its stated goals, with $67 \%$ agreeing to a great extent and $26 \%$ agreeing to a certain degree.

However, we found different results for technological and organizational success. Overall, the indicators for technology and organization show that, on average, the respondents agree to a certain degree ( $24 \%$ and $29 \%$ ) or to a great extent ( $48 \%$ and $56 \%$ ) that the project was a success technologically and organizationally, respectively.

In addition, we found that close to a quarter to one third of respondents do not agree or are not sure that the project enables the creation of interoperable systems and networks, the creation of information system that can communicate with each other, and the creation of integrated databases into new data resources. We also found that around $19-22 \%$ of the respondents do not agree or are not sure that IIS projects result in an organization having greater effectiveness in deliberating policy, improving government daily operations, and in achieving costs saving. The results demonstrate that the perceptions of the stakeholder vary depending on how success was measured. Thus, how the role of trust affects the different perceptions of stakeholders regarding the success of an IIS project is also expected to be influenced by how success is measured

\subsection{The Fit of the Model}

We started by evaluating whether our proposed theoretical model (Figure 1) is a fit model based on the survey data. We present the goodness-o $3 \mathrm{t}$ measure in Table 2 . The results indicate that in all models, the fitnes 3 est signifies an adequate fit for most of the information criteria. Results from the structural analysis 3 icate that the tested models provide adequate explanations for the structural relationships among variables. For instance, the $\chi^{2}$ significance (p) value on average for the four models is above the $\chi 2$ cut-off value of 0.05 , meaning that the model has a good fit. The p-value of chi-square for technology success and organizational success show values of less than 0.05 , which signify a less fit model.

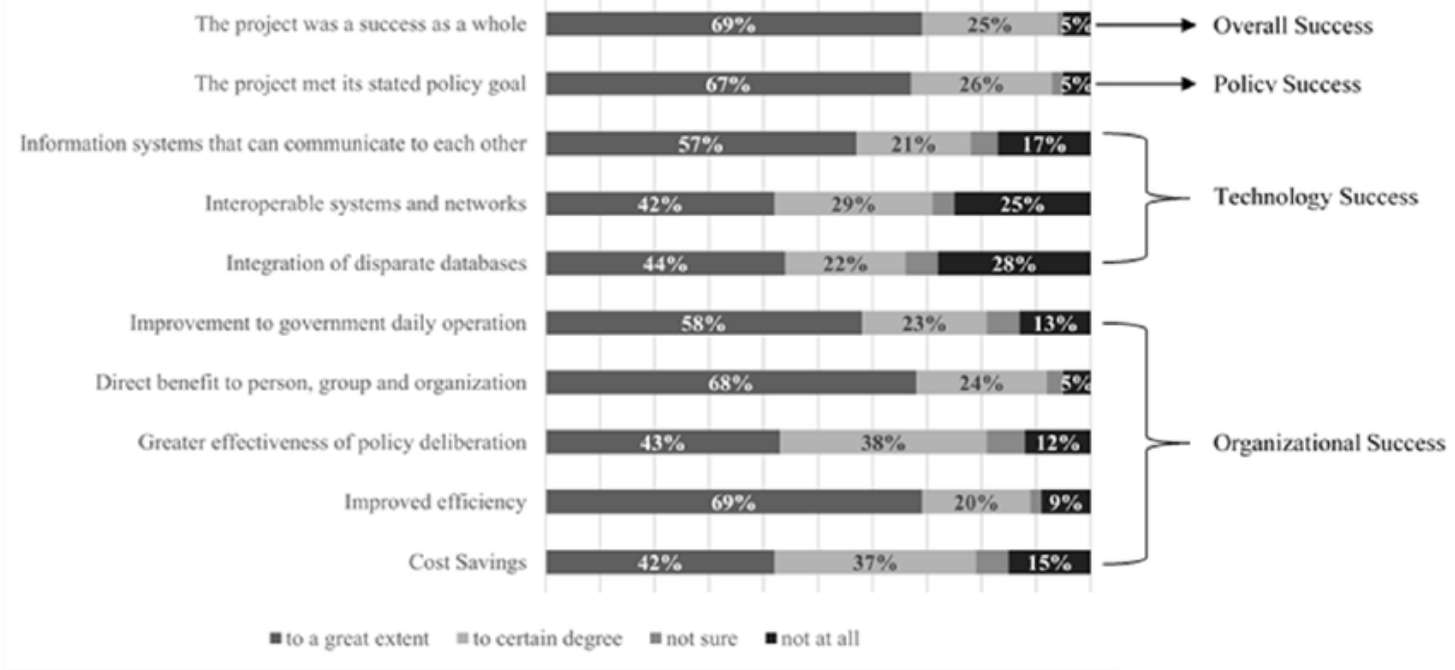

Figure 2. The Measurement of IIS Success 
However, the other information criteria for technology and organizational success indicate an adequate fit. For instance, if measured by RMSEA, or the "badness of fit" index, the average value is below 0.10 and indicates an approximate good fit of the model. The fit indexes (GFI, NFI, and CFI) are all above the threshold of 0.90 , further signifying an overall good fit.

Table 2. Model Goodness-of-Fit

\begin{tabular}{|c|c|c|c|c|c|}
\hline $\begin{array}{l}\text { Model } \\
\text { goodness-of- } \\
\text { fit indexes }\end{array}$ & $\begin{array}{c}\text { Cut- } \\
\text { off } \\
\text { values }\end{array}$ & $\begin{array}{l}\text { Overall } \\
\text { Success }\end{array}$ & $\begin{array}{l}\text { Policy } \\
\text { Success }\end{array}$ & $\begin{array}{l}\text { Tech. } \\
\text { Success }\end{array}$ & $\begin{array}{l}\text { Org. } \\
\text { Success }\end{array}$ \\
\hline$x^{2}$ & $\begin{array}{c}<< \\
x^{2} \text { table }\end{array}$ & 9.035 & 4.335 & 15.06 & 11.85 \\
\hline $\begin{array}{l}\chi^{2} \text { significance } \\
\text { (p) } \\
3\end{array}$ & $p>.05$ & 0.107 & 0.502 & 0.010 & 0.034 \\
\hline $\begin{array}{l}\text { Goodness-of- } \\
\text { fit index (GFI) } \\
3\end{array}$ & $\geq 0.90$ & 0.984 & 0.992 & 0.974 & 0.979 \\
\hline $\begin{array}{l}\text { Normed fit } \\
\text { index (NFI) } \\
3\end{array}$ & $\geq 0.90$ & 0.957 & 0.979 & 0.927 & 0.946 \\
\hline $\begin{array}{l}\text { Comparative } \\
\text { Fit Index } \\
3\end{array}$ & $\geq 0.90$ & 0.979 & 1.000 & 0.946 & 0.965 \\
\hline $\begin{array}{l}\text { Incremental } \\
\text { Fit Index (IFI) }\end{array}$ & $\geq 0.90$ & 0.980 & 1.000 & 0.950 & 0.968 \\
\hline RMR & $\leq 0.10$ & 0.042 & 0.029 & 0.057 & 0.048 \\
\hline $\begin{array}{l}\text { RMSEA } \\
3\end{array}$ & $\leq 0.10$ & 0.073 & 0.000 & 0.011 & 0.094 \\
\hline $\begin{array}{l}\text { p-value of } \\
\text { RMSEA }\end{array}$ & $p>.05$ & 0.256 & 0.692 & 0.048 & 0.124 \\
\hline
\end{tabular}

\subsection{The Determinants of Trust in IIS Projects}

The results as show 1 in Table 3 indicate three direct and two indirect significant determinants of trust. Clarity of roles and responsibilities, past experiences, and effective communication significantly and directly influence trust and indirectly influence IIS success. Clarity of roles and responsibilities directly and significantly influences the formation of trust in the IIS collaboration at the $99 \%$ confidence interval with a t-value of 3.309 for overall success, a t-value of 3.247 for policy success, a t-value of 3.235 for technological success, and a t-value of 3.238 for organizational success. While the magnitude of the coefficient estimates changes for some variables depending on the measurement of success, the results indicate that the coefficients of clarity of roles and responsibilities to trust remain relatively stable regardless of the measurement of success.

Past experience is found to have a significant influence on trust for all measurements of success. The results also indicate that the coefficient magnitude is higher when success is measured as technological success. This suggest that past experiences matter more to induce trust for a project when success is measured using technology variables. Presumably participants equate past experiences with a potential reduction of risks; having past experiences is assumed to be more important to support the successful completion of the technology-related goals in IIS projects. As expected, effective communication significantly influences the formation of trust both directly and indirectly, through clarity of roles and responsibilities. Effective communication influences trust in IIS for all measurements of success at the $99 \%$ confidence interval with a t-value of 5.780 for overall success, a t-value of 5.873 for policy success, a t-value of 5.881 for technological success, and a t-value of 5.871 for organizational success. The results further indicate that the influe 1 ce of communication on trust is higher when mediated by the clarity of roles and respo 1 ibilities as shown from its coefficient's magnitude. Finally, knowledge of other participating organizations influences the formation of trust indirectly as mediate 1 by clarity of roles and responsibilities. This means that having knowledge of other participating organizations facilitates the creation of clear roles and responsibilities, which in turn induces the formation of trust in the IIS collaboration

\subsection{The Mediating Roles of Trust to IIS Project Success}

In this section, we tested the extent to which trust plays a significant role in mediating the stakeholder's perceptions of how success was formed. Our results in Table 3 show the significant role of trust on the success of IIS, both directly and in mediating the influence of other variables depending on how success is measured. The results show that the role of trust is less significant when success is measured only as technological success. We also found that the magnitude of the coefficient estimates changes for some variables depending on the measurement of success (see Table 3 below).

Trust significantly and directly influences the success of IIS except when success is measured as technological success only. The results show that trust significantly and directly influences the success of IIS at the $99 \%$ confidence level for overall success (with a t-value of 3.306) and for organizational success (with a t-value of 3.125 ) and at the $95 \%$ confidence level for policy success (with a tvalue of 2.312). Trust is significant in mediating the relationships between clarity of roles and responsibilities and success of IIS except for technological success; with a t-value of 2.370 for overall success, a t-value of 1.908 for policy success, and a t-value of 2.278 for organizational success. The results thus indicate that clarity of roles and responsibilities facilitate the creation of trust and in turn trusted relationships in the collaboration, which contribute to the success of IIS.

The role of trust is also significant in mediating the influence of how participants exercise authority in the IIS collaboration, but only when IIS success is measured as overall success and policy success, with a t-value of 1.96 for overall success and a t-value of 3.25 for policy success. The coefficient of the relationship connecting exercise of authority, trust, and success of IIS is negative because exercise of authority is measured as participants misusing their authority in this study. Thus, a negative notation indicates that when participants misuse the authority bestowed to them, it will erode trust relationships among participants and could eventually could lead to an unsuccessful IIS project. Comparing the magnitude of the coefficients, the influence of misuse of authority on eroding trust and success of IIS is stronger (coeff -0.254 ) when success is measured as policy success as compared to overall success. 
Table 3. Structural Parameter Estimates

\begin{tabular}{lrrrrrrrr}
\hline \multicolumn{1}{c}{ Path Coefficients } & Overall Success & Policy Success & \multicolumn{2}{c}{ Tech. Success } & \multicolumn{2}{c}{ Org. Success } \\
\hline Trust $\rightarrow$ Success & 0.279 & $* *$ & 0.192 & $*$ & 0.070 & - & 0.260 & $* *$ \\
CRR $\rightarrow$ Trust & 0.230 & $* *$ & 0.224 & $* *$ & 0.223 & $* *$ & 0.223 & $* *$ \\
CRR $\rightarrow$ Trust $\rightarrow$ Success & 0.064 & $* *$ & 0.043 & $*$ & 0.016 & - & 0.058 & $*$ \\
Authority $\rightarrow$ Trust $\rightarrow$ Success & -0.157 & $*$ & -0.254 & $* *$ & -0.063 & - & -0.021 & - \\
Experiences $\rightarrow$ Trust & 0.154 & $* *$ & 0.153 & $* *$ & 0.157 & $*$ & 0.155 & $*$ \\
Experiences $\rightarrow$ Trust $\rightarrow$ Success & -0.028 & - & -0.069 & - & 0.106 & - & 0.181 & $*$ \\
Comm. $\rightarrow$ Trust & 0.422 & $* *$ & 0.425 & $* *$ & 0.425 & $* *$ & 0.424 & $* *$ \\
Comm. $\rightarrow$ CRR & 0.422 & $* *$ & 0.423 & $* *$ & 0.427 & $* *$ & 0.427 & $* *$ \\
Comm $\rightarrow$ CRR $\rightarrow$ Trust & 0.520 & $* *$ & 0.520 & $* *$ & 0.520 & $* *$ & 0.519 & $* *$ \\
Comm $\rightarrow$ CRR $\rightarrow$ Trust $\rightarrow$ Success & 0.145 & $* *$ & 0.100 & $*$ & 0.037 & - & 0.135 & $*$ \\
Know. Part. Org $\rightarrow$ CRR & 0.184 & $* *$ & 0.176 & $*$ & 0.240 & $*$ & 0.176 & $*$ \\
Know. Part. Org $\rightarrow$ CRR $\rightarrow$ Trust & 0.129 & $*$ & 0.136 & $*$ & 0.134 & $*$ & 0.135 & $*$ \\
\hline
\end{tabular}

** indicate significant at 0.01 level; $*$ indicate significant at 0.05 level

Past experiences significantly and directly influence the building of trust regardless of how success is measured. Trust is crucial, however, in mediating the relationship between a participant's past experiences and the success of the IIS project only when success is measured as organizational success, with a tvalue of 2.312. The results indicate that trust also mediates the influence of effective communication on the success of IIS through the clarity of roles and responsibilities, except when success is measured as technological success. These results suggest that effective communication can facilitate the creation of CRRs, which in turn encourages the building of trust that subsequently influences the success of IIS.

The results in Table 3 show that the relationships among effective communication, clarity of roles and responsibilities, trust, and success are significant with a t-value of 3.067 for overall success, a t-value of 2.241 for policy success, and a t-value of 2.931 for organizational success. On the other hand, we found that trust is not significant in mediating the relationship between knowledge of other participating organization and the success of IIS. The fact that the participants are knowledgeable about the other participating organizations does not lead to the creation of trust and subsequently to the achievement of success of IIS projects. Although the results indicate that knowledge about other 1.rticipating organizations significantly and directly influences the clarity of roles and responsibilities. Likewise, knowledge about other participating organizations significantly but indirectly influences the building of trust through CRRs for all measurements of success at the $95 \%$ confidence intervals.

\section{DISCUSSION AND IMPLICATIONS}

Even though trust is frequently considered to be an influencing factor in inter-organizational collaboration, research to identify and empirically test the determinants and the roles of trust in interagency information sharing is much less common [12]. Studies by Pardo, Gil-Garcia and Burke [30] and Gil-Garcia, Guler, Pardo and Burke [12] identified and proposed three determinants of trust based on qualitative analysis of IIS cases in the public sector. The purpose of the present study is to systematically evaluate, through statistical analysis, the determinants of trust and the roles of trust in mediating the determinants of success in IIS initiatives across different jurisdictions and levels of government.
Our findings on the effects of trust are not only consistent with prior studies, but also offers new empirical findings on the mediating role of trust in determining the success of IIS projects in the public sector.

Our results broadly support the thesis that trust acts as the mediator between some specific determinants and the success of IIS projects. The results from the Structural Equation Modeling analysis showed that trust significantly mediates the relationships of clarity of roles and responsibilities, effective communication, past experiences, and the exercise of formal authority with the success of IIS projects. Our findings suggest the following four variables as affecting trust and consequently IIS success: a) effective communication, b) having clarity about the roles, responsibilities, and expectations of themselves and others, c) competence inferred from past experiences, and d) judicious exercise of formal authority.

The formation of trust, from 1 employing effective communications and dialogues and also having a clear sense of roles and responsibilities, increases the participants' awareness of how risks will be minimized and how the collaboration will be governed, which will eventually contribute to the project's success. In this sense, trust provides assurance and security to the participants [42]. As such, the existence of trust in the IIS collaboration allows the participants to manage their regular activities without having to assess all the possible uncertainties and risks that they cannot control when joining the IIS collaboration [33, 34, 42]. Particularly, clarity of roles and responsibilities enables the development of swift trust, which is crucial in IIS collaboration given that the structuring of authority in such a collaboration develops gradually [32]. Swift trust refers to the formation of trust in temporary and/or time-constrained organizations $[6,25]$. The development of swift trust served as the glue that cemented the relationships among the par 1 i ipants in interorganizational collaboration [42]. In contrast, the lack of clarity of roles and responsibilities led to distrust among the participants, which can subsequently affect the success of an IIS project $[12,30]$.

Our results show the significant role of trust in mediating the relationship between effective communication and IIS success. The uncertainties regarding partnership boundaries in IIS collaboration need to be resolved early in the collaboration. Much of the success in negotiating the boundaries and establishing trust depend on 
communication among the participants [17]. Developing trust to mitigate uncertainties and risk in IIS initiatives occurs via intensive conversations among the participants in the collaboration [15]. Participants need to have effective communication to reach consensus and shared understandings that could lead to trust and eventually IIS project success. This result confirms findings from other studies arguing for the role of trust in mediating communication and the outcomes of technology-based projects [21, $35]$.

Our findings also indicate that trust significantly mediates the relationship between past experiences and the success of IIS. It is argued that competence is one operationalization of trust in collaboration [4]. Arguably, past experiences could be seen as competence, hence they could signify the skills that participants have gathered with regard to IIS collaborations. Hyder and Ghauri [18] claim that experiences and prolonged interactions among partners reduce the perceptions of uncertainty in the collaboration. In this sense, we posit that having previous experiences with collaboration increase trust by reducing the perceptions of uncertainties among the participants, which then could lead to the successful completion of the IIS collaboration. Finally, consistent with Pardo et al. [30] and Gil-Garcia et al. [12], our findings provide empirical evidence of how the exercise of authority by certain participants affects trust among all other participants in an IIS initiative. The results indicate that misuse or improper use of authority create distrust, potentially leading to the failure of an IIS collaboration.

\section{CONCLUSIONS}

Interagency collaboration and information sharing projects in the public sector represents a complex enterprise. In such an environment, public officials need to go beyond their respective agency's boundaries to negotiate and reach an agreement about how the collaboration should proceed. Crossing organizational boundaries creates fear and risks that stem from the uncertainties and complexities of the IIS initiative. Past research argues that trust is one of the crucial components in mitigating the risks of collaboration and ensuring success (see for instance, Ring \& Van der Ven, [33]; [34]; Van de Ven \& Ring, [42]). Our findings confirm that trust is a significant mediator in the relationship between certain variables and the success of IIS projects. More specifically, we found that trust is significant in mediating the link between four determinants of IIS success: a) effective communication, b) clarity of roles and responsibilities, c) competence inferred from past experiences, and d) judicious exercise of formal authority, which reduces the participants' uncertainty and anxiety about the project. Furthermore, our results indicate that the significance of trust in mediating the relationships between these variables and IIS success depend on how that success is measured. We argue that 1 ting the role of trust through a solid quantitative approach makes an important contribution to the literature as well as to government practice.

This discussion also helps government practitioners to better understand which factors determine the creation of trust and that subsequently lead to the success of an IIS project. Furthermore, given that we found the effect of trust depends on how the participants perceived the measurement of IIS project success, government officials involved in IIS projects could use these results to manage the development of trust in IIS project. For instance, if success is measured in terms of technology development, such as the implementation of a financial module in an enterprise resource planning system, the role of trust is less important than if the project's success is measured through an organizational lens. Thus, participants or project managers could adjust their efforts and manage their resources in a better way to meet their definition of success.

The results of this study also reaffirm the propositions from prior qualitative analysis regarding the role of trust in IIS settings by providing solid empirical quantitative evidence. Our results also open the possibilities for future research to corroborate its findings. For instance, although we found the magnitude of the coefficient differs among the four measurements of success, we cannot be sure how important this difference is in theory and practice. Future research could use differential statistics to test whether the influence of trust indeed varies among the different measurements of success.

\section{ACKNOWLEDGMENTS}

This work was partially supported by the National Science Foundation under Grant No. ITR-0205152 and by the Direktorat Jendral Penguatan Riset 4hd Pengembangan (Ristek Dikti) of the Republic of Indonesia. Any opinions, findings, conclusions, or recommendations expressed in this material are those of the authors and do not necessarily reflect the views of the National Science Foundation or the Ristek Dikti.

\section{REFERENCES}

[1] Sulin Ba \& Paul A. Pavlou. 2002. Evidence of the Effect of Trust Building Technology in Electronic Markets: Price Premiums and Buyer Behavior. MIS Q., 26, 3, 243-268. https://doi.org/10.2307/4132332

[2] Reinhard Bachmann. 2003. The Coordination of Relations Across Organizational Boundaries. Int. Stud. Manag. Organ., $33,2,7-21$.

[3] Katinka Bijlsma \& Paul Koopman. 2003. Introduction: trust within organisations. Pers. Rev. 32, 5, 543-555. https://doi.org/10.1108/00483480310488324

[4] Margreet F. Boersma, Peter J. Buckley \& Pervez N. Ghauri. 2003. Trust in international joint venture relationships. J. Bus. Res., 56, 12, 1031-1042. https://doi.org/10.1016/S01482963(01)00315-0

[5] Mary Casey. 2008. Partnership - success factors of interorganizational relationships. J. Nurs. Manag., 16, 1, 72 83. https://doi.org/10.1111/j. 1365-2934.2007.00771.x

[6] Steven Curnin, Christine Owen, Douglas Paton, Cain Trist \& David Parsons. 2015. Role Clarity, Swift Trust and MultiAgency Coordination. J. Contingencies Crisis Manag., 23, 1, 29-35. https://doi.org/10.1111/1468-5973.12072

[7] T. K. Das \& Bing-Sheng Teng. 1998. Between Trust and Control: Developing Confidence in Partner Cooperation in Alliances. Acad. Manage. Rev., 23, 3, 491-512. https://doi.org/10.5465/AMR.1998.926623

[8] Sharon S. Dawes, 1996. Interagency Information Sharing: Expected Benefits, Manageable Risks. J. Policy Anal. Manage, , 15, 3, 377-394.

[9] Sharon S. Dawes, Anthony M. Cresswell \& Theresa A. Pardo 2009. From "Need to Know" to "Need to Share": Tangled Problems, Information Boundaries, and the Building of Public 
Sector Knowledge Networks. Public. Adm. Rev., 69, 3, 392 402 .

[10] Ophelia Eglene, Sharon S. Dawes, \& Carrie A. Schneider. 2007. Authority and Leadership Patterns in Public Sector Knowledge Networks. Am. Rev. Public Adm., 37, 1, 91-113. https://doi.org/10.1177/0275074006290799

[11] J. Ramon Gil-Garcia, Ahmed Guler, Theresa A. Pardo, \& Brian G. Burke. 2010. Trust in Government Cross-Boundary Information Sharing Initiatives: Identifying the Determinants. In 2010 43rd Hawaii International Conference on System Sciences, IEEE Digital Library, 1-10.

[12] J. Ramon Gil-Garcia, Theresa A. Pardo, \& Brian G. Burke. 2010. Conceptualizing Information Integration in Government. In H. J. Scholl (Ed.), E-Govemment: Information, Technology, and Transformation (p. 346). M.E. Sharpe.

[13] Ranjay Gulati. 1998. Alliances and networks. Strateg. Manag. J., 19, 4, 293-317.

[14] Joanna Gutierrez, 2014. Establishing a Conceptual Framework for Interagency Coordination at U.S. Southern Command - ProQuest. Prism J. Cent. Complex Oper. 5, 1, $136-153$.

[15] Cynthia Hardy, Thomas B. Lawrence, \& David Grant. 2005. Discourse and Collaboration: The Role of Conversations and Collective Identity. Acad. Manage. Rev., 30, 1, 58-77. https://doi.org/10.5465/AMR.2005.15281426

[16] Paul Hart \& Carol Saunders. 1997. Power and Trust: Critical Factors in the Adoption and Use of Electronic Data Interchange. Organ. Sci., 8, 1, 23-42.

[17] Jan Horwath \& Tony Morrison. 2007. Collaboration, integration and change in children's services: critical issues and key ingredients. Child Abuse \& Negle., 31, 1, 55-69.

[18] Akmal S. Hyder \& Pervez N. Ghauri. 2000. Managing Intermational Joint Venture Relationships: A Longitudinal Perspective. Ind Mark. Manage., 29, 3, 205-218. https://doi.org/10.1016/S00 19-8501(98)00054-6

[19] Eva C. Kasper-Fuehrera \& Neil M. Ashkanasy. 2001. Communicating trustworthiness and building trust in interorganizational virtual organizations. J. Manag., 27, 3, 235-254. https://doi.org/10.1177/014920630102700302

[20] Richard Leifer \& Peter K Mills. 1996. An information processing approach for deciding upon control strategies and reducing control loss in emerging organizations. J. Manag., $22,1,113-137$.

[21] Luis F. Luna-Reyes. 2006. Trust and Collaboration in Interagency Information Technology Projects. SSRN Working Paper.

[22] Luis F. Luna-Reyes, Laura J. Black, Anthony M. Cresswell, \& Theresa A. Pardo, 2008. Knowledge sharing and trust in collaborative requirements analysis. Syst. Dyn. Rev., 24, 3, 265-297. https://doi.org/10.1002/sdr.404

[23] Diana R.S. Martinez, Tirso J.H. Gracia, Enrique M. Muñoz \& Alejandra C. García. 2017. Smart Cities' Challenge: How to Improve Coordination in the Supply Chain. In Sustainable Smart Cities (pp. 129-142). Springer. Retrieved from http://link.springer.com/chapter/10.1007/978-3-319-408958_10
[24] Roger C. Mayer, James H. Davis \& David F. Schoorman 1995. An Integrative Model Of Organizational Trust. Acad. Manage. Rev., 20, 3, 709-734.

[25] Debra Meyerson, Karl E. Weick \& Roderick M. Kramer 1995. Swift Trust and Temporary Groups. In Roderick M Kramer \& Tom R. Tyler (Eds.), Trust in Organizations: Frontiers of Theory and Research. SAGE Publications.

[26] Linda Milbourne, Sheila Macrae \& Meg Maguire. 2003 Collaborative solutions or new policy problems: exploring multi-agency partnerships in education and health work. $J$. Educ. Policy, 18, 1, 19-35.

[27] Helle Neergaard \& John P. Ulhøi. 2006. Government Agency and Trust in the Formation and Transformation of Interorganizational Entrepreneurial Networks. Entre. Theory Pract., 30, 4, 519-539. https://doi.org/10.1111/j.15406520.2006.00133.x

[28] Elinor Ostrom. 1998. A Behavioral Approach to the Rational Choice Theory of Collective Action: Presidential Address, American Political Science Association, 1997. Am. Polit. Sci. Rev. 92, 1, 1-22. https://doi.org/10.2307/2585925

[29] Theresa A. Pardo, Brian G. Burke, J. Ramon Gil-Garcia \& Ahmed Guler. 2009. Clarity of roles and responsibilities in government cross-boundary information sharing initiatives: Identifying the determinants. In Proceedings of 5th International Conference on e-Government (pp. 148-155).

[30] Theresa A. Pardo, J. Ramon Gil-Garcia \& Brian G. Burke. 2006. Building response capacity through cross-boundary information sharing: The critical role of trust. In Exploiting the knowledge economy: Issues, applications, case studies (pp. 507-514). Barcelona, Spain.

[31] Keith G. Provan \& H. Brinton Milward. 1999. Do Networks Really Work?: A Framework for Evaluating Public-Sector Organizational Networks. Acad. Manage. Proc. 1, A1-A6. https://doi.org/10.5465/APBPP.1999.27628083

[32] Karl R. Rethemeyer \& Daneen M. Hatmaker. 2008. Network Management Reconsidered: An Inquiry into Management of Network Structures in Public Sector Service Provision. J. Public Adm. Res. Theory, 18, 4, 617-646.

[33] Peter Smith Ring \& Andrew H. van de Ven. 1992. Structuring cooperative relationships between organizations. Strateg. Manage. J., 13, 7, 483-498.

[34] Peter Smith Ring \& Andrew H. Van De Ven. 1994 Developmental Processes of Cooperative Interorganizational Relationships. Acad. of Manage. Rev., 19, 1, 90-118 https://doi.org/10.5465/AMR.1994.9410122009

[35] Michael D. Santoro \& Patrick A. Saparito. 2003. The firm's trust in its university partner as a key mediator in advancing knowledge and new technologies. IEEE Trans. Eng. Manag., 50, 3, 362-373. https://doi.org/10.1109/TEM.2003.817287

[36] Djoko S. Sayogo, J. Ramon Gil-Garcia \& Felippe Cronemberger. 2016. Determinants of Clarity of Roles and Responsibilities in Interagency Information Integration and Sharing (IIS). In H. J. Scholl, O. Glassey, M. Janssen, B. Klievink, I. Lindgren, P. Parycek, ... D. S. Soares (Eds.), Electronic Government (pp. 126-134). Springer International Publishing. https://doi.org/10.1007/978-3-319-44421-5_10

[37] Hans J. Scholl \& Margit C. Scholl. 2014. Smart Governance: A Roadmap for Research and Practice. In iConference 2014 Proceedings (pp. 163-176). https://doi.org/10.9776/14060 
[38] Jagdip Singh. 1993. Boundary Role Ambiguity: Facets, Determinants, and Impacts. J. Mark., 57, 2, 11-31. https://doi.org/10.2307/1252024

[39] Jorg Sydow, 1998. Understanding the constitution of interorganizational trust. Trust within and between Organizations: Conceptual Issues and Empirical Applications, $31-63$.

[40] Owen Temby, Archi Rastogi, Jean Sandall, Ray Cooksey \& Gordon M. Hickey. 2015. Interagency Trust and Communication in the Transboundary Governance of Pacific Salmon Fisheries. Rev. Policy Res., 32, 1, 79-99.

[41] Ann Marie Thomson \& James L. Perry. 2006. Collaboration Processes: Inside the Black Box. Public Adm. Rev., 66, 20-32. https://doi.org/10.1111/j.1540-6210.2006.00663.x
[42] Andrew H. Van de Ven \& Paul Smith Ring. 2006. Relying on Trust in Cooperative Inter-Organizational Relationships. In R. Bachmann \& A. Zaheer (Eds.), Handbook of Trust Research (pp. 144-164). Northhampton, MA, USA: Edward Elgar Publishing.

[43] Siv Vangen \& Chris Huxham. 2003. Nurturing Collaborative Relations: Building Trust in Interorganizational Collaboration. J. Appl. Behav. Sci., 39, 1, 5-31. https://doi.org/10.1177/0021886303039001001

[44] Tong-Mou Yang \& Terrence A. Maxwell. 2011. Informationsharing in public organizations: A literature review of interpersonal, intra-organizational and inter-organizational success factors. Gov. Inf. Q., 28, 2, 164-175. https://doi.org/10.1016/j.giq.2010.06.008 
The Mediating Role of Trust for Inter-Organizational Information Sharing (IIS) Success in the Public Sector

ORIGINALITY REPORT

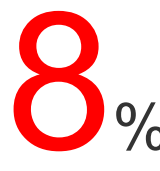

SIMILARITY INDEX
$4 \%$

INTERNET SOURCES

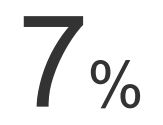

PUBLICATIONS
$2 \%$

STUDENT PAPERS

J. Ramon Gil-Garcia, Ahmet Guler, Theresa A.

Pardo, G. Brian Burke. "Trust in Government

Cross-Boundary Information Sharing Initiatives:

Identifying the Determinants", 2010 43rd

Hawaii International Conference on System

Sciences, 2010

Publication

2 Yiwei Gong, Marijn Janssen. "Enterprise

Architectures for Supporting the Adoption of

Big Data", Proceedings of the 18th Annual

International Conference on Digital

Government Research - dg.o '17, 2017

Publication

3 Djoko Sigit Sayogo, Theresa A. Pardo.

"Exploring the Motive for Data Publication in

Open Data Initiative: Linking Intention to

Action", 2012 45th Hawaii International

Conference on System Sciences, 2012

Publication

www.ctg.albany.edu 
Exclude bibliography On 